\title{
Toward Establishing the Productive Chain for Triterpene-Based Amazonian Oleoresins as Valuable Non-Timber Forest Products
}

\author{
Antonio C. Siani ${ }^{*}$, Roseane Moraes², Valdir F. Veiga Junior ${ }^{2}$ \\ ${ }^{1}$ Institute of Drug Technology, Oswaldo Cruz Foundation, Rio de Janeiro, Brazil \\ ${ }^{2}$ Chemistry Department, Amazonas Federal University, Manaus, Brazil \\ Email: *siani@far.fiocruz.br
}

How to cite this paper: Siani, A. C., Moraes, R., \& Veiga Junior, V. F. (2017). Toward Establishing the Productive Chain for Triterpene-Based Amazonian Oleoresins as Valuable Non-Timber Forest Products. Open Journal of Forestry, 7, 188-208.

https://doi.org/10.4236/ojf.2017.72012

Received: February 3, 2017

Accepted: April 10, 2017

Published: April 13, 2017

Copyright $\odot 2017$ by authors and Scientific Research Publishing Inc. This work is licensed under the Creative Commons Attribution International License (CC BY 4.0).

http://creativecommons.org/licenses/by/4.0/

\begin{abstract}
In the Amazonian rainforest, many species of Burseraceae known locally as "breu" are explored for the medicinal and aromatic uses of their trunk exudates. This material also has a long-standing use by the forest communities in building and caulking boats as well as in the making of wooden utensils and general crafts. Breu are strongly aromatic due volatile terpenes in their composition that are separated from the crude resin by steam distillation. The remaining residue amorphous "hard resin" is primary used for application in woodworking. Despite the potential for application in paints, varnishes and odor fixatives, the commercialization of the hard resin has not surpassed the local market level. In order to achieve and establish a more valorized market for this Amazonian non-timber forest product, the existing and potential demands need to be estimated, a draft of the production chain needs to be drawn up and care needs to be taken to provide products of the highest possible quality. This study aimed to identify and organize the main issues necessary for the attainment of these goals and its value chain, and identify the technologies that would improve the quality of the Amazonian breu as a raw material. A review of the data available in the literature and the analytical techniques that could be applied to generate standards for the extraction, purification, and analysis of the hard resin fraction was made. Quality issues based on physicochemical standards might affect the productive chain by: i) helping to consolidate the appropriate methodologies for collecting and storing the raw material; ii) adding value and qualifying the primary improvement processes and iii) supporting the certification of the raw materials for commercialization. Potentiate this material to reach high-level markets might boost the production demand and improve the rain forest communities' income.
\end{abstract}




\section{Keywords}

Burseraceae, Breu, Terpenoid Resins, Productive Chain, Technological Value Aggregation

\section{Introduction}

Since ancient times, plant exudates referred to as "resins" have been used by mankind for diverse applications in handcrafts, as well as for religious and medicinal purposes. The generic term resin comprises distinct materials, depending on the botanical origin and chemical constitution. Resins can be defined as a complex mixture of secondary metabolites secreted and stored by internal or specialized surface structures located in plant organs that play some specific ecological role (Langeheim, 2003). The terpenoid classes make up the largest and most well-known category of resins. Their lipophilicity, characteristic fluidity and malleability, due to the mixture of volatile (mono- and sesquiterpene) and nonvolatile (di- and triterpene) compounds, has led them being better known as "oleoresins". Species of the family Burseraceae are the main source of oleoresins around the world; the most representative belonging to the Asiatic and African genera Commiphora (myrrh), Canarium (elemi incense), and Boswellia (frankincense or olibanum), in addition to the genera Bursera (linaloe), Dacryodes, Trattinickia, and Protium (almécega, breu). Most of these latter are pantropical, although some can also be found condensed in specific regions of South America (Daly, 2007). Such is the case for Protium, which is by far the largest genus in the Neotropics, comprising about 135 species (Rüdiger et al., 2007). Protium and Trattinickia species are widely distributed throughout the Brazilian forests, where their resins are popularly known as "breu".

A variable mixture of monoterpenes and triterpenes constitutes breu (Rüdiger et al., 2007). Pinane- and menthane-type compounds (e.g. limonene, phellandrene, cymene, etc.) mostly constitute its volatile fraction (Khalid, 1983). This latter can be separated out from the nonvolatile triterpene mixture by techniques as simple as steam distillation (Siani et al., 1999; Ramos et al., 2000). This essential oil finds applications in the flavor and fragrance industries; e.g. in perfumery and cosmetics, ingredients for hygiene and antiseptic products, etc. (Murthy et al., 2016). The crude breu is also often used as incense for ritualistic purposes (Case et al., 2003; Langenheim, 2003).

The non-volatile fraction is what remains once the volatile compounds from the crude oleoresins are removed (Siani et al., 2012) and its utilities allow this raw material to bring about perspectives in order to expand and diversify the breu's market. In general, regardless of the origin or composition, triterpenes from ursane and oleanane series ( $\alpha$ - and $\beta$-amyrin derivatives) are largely predominant in these mixtures (Rüdiger \& Veiga-Junior, 2013). This amorphous product ("hard resin") is quite viscous, brownish in color, and can be further re- 
fined by recrystallization (Costa, 1975) to furnish yellowish to white powders (still comprising mixtures of triterpenes), or by other techniques (Susunaga et al., 2001; Vieira et al., 2005; Rudiger \& Veiga-Júnior, 2009; Marques et al., 2010; Hernández-Vázquez et al., 2010).

The ethnographic registers of hard resins reveal the relevance of their use in ship building and maintenance as high-resistant caulking materials and waterproofing varnishes or for coating sensitive materials. These applications have been well documented in relation to rosin (tar) from pine resin (Coppen \& Hone, 1995) by early European and Asian sailors (Langeheim, 2003). A parallel could undoubtedly be drawn to neotropical Burseraceae resins since they have been likewise employed for the same purposes (Le Cointe, 1947; Costa, 1975; Rizzini \& Mors, 1995); although, depending on the species, such an assertion would be based on scarce ethnobotanical information (Pernet, 1972; Corrêa, 1984; Lago et al., 2016). Other important uses of resins by South America forest communities include the burning of crude breu to produce insect-repellent smoke (Frisk, 1995; Rhind, 2013) as well as the use of breu in applications for medicinal purposes that include, among others, stimulant and anti-septic activities (Costa, 1975; Corrêa, 1984). Furthermore, breu is used as palliative for restoring decaying teeth (Lewis \& Elvin-Lewis, 1977) or to avoid worsening of broken bones, as well as a component of plasters and general ointments for topical applications (Costa, 1975; Corrêa, 1984).

The ethnobotanical information on breu in South America usually refers to the utilization of the crude exudates, i.e. a natural mixture of triterpenes dissolved in a mixture of monoterpenes. The variable proportions between the nonvolatile and volatile compounds would define the softness and malleability of the material, and thereafter its use for specific purposes (Costa, 1975). Obviously, the more aged the collected breu, the harder (and less pungent) it will be. On the other hand, following the steam distillation of hardened breu, it is not rare to find phenylpropanoid compounds (e.g. elemicin, dillapiole or analogs) as "contaminants" in the monoterpene mixture. Phenylpropanoids are not produced by the same biosynthetic routes in the plants (Langenheim, 2003) and, being less volatile than monoterpenes, they tend to remain in the hard resins, lending them particular aromas (Siani et al., 1999).

The commercialization potential of resins relates to their composition, which ultimately defines their applications (Carranza \& Alejandro, 2015). For instance, specialized uses for rosin are based on its diterpene acid content, while applications of the volatile part (turpentine) are determined by its high monoterpene content (Langenheim, 2003). Variable compositions, such as those of crude breu, are less attractive commercially than mixtures with a more constant mono- or triterpene composition. Sold separately, the volatile and nonvolatile fractions should be able to meet the demands of various and distinct markets and, consequently, boost the value of the raw materials. This step is fundamental for sustaining social projects based on breu trade.

Any kind of tool applied aiming at improving product quality or certifying the 
sustainability process will strongly contribute toward establishing breu production as a viable and valuable non-timber forest products NTFP (HernándezVázquez et al., 2010). The development of proper management systems is therefore essential to attain certification and to strengthen the productive chain, even in the early stages of its development. In this respect, studies and projects directed at these issues should be guided by multidisciplinary criteria, both to raise the quality of the raw material by applying knowledge and existing technologies, and to improve human practices and general management.

The commercialization of resins has been the concern of the Food and Agriculture Organization (FAO) of the United Nations, which has produced, in the mid-1990's a series of studies on commercially important NTFP from around the world. These NTFP include gums, resins, and latexes (Coppen, 1995a). This FAO initiative has led to the adoption of a standard format for describing the most relevant parameters of the production chains that will support trading and sustainable use. These parameters are: 1) description and uses; 2) world supply and demand trends; 3) plant sources; 4) collection/primary processing; 5) value-adding processing; 6 ) products other than gum, resin or latex (by the producing plant); 7) development potential; and 8) selected bibliography.

The present article aims to create the background for the inclusion of breu (mainly from Protium and Trattinickia species exudates) as a valuable Amazonian NTFP. Some perfume and fragrance companies that work on specific species are already exploiting the volatile fraction of breu; however, no data are available on the potential markets for the nonvolatile resins obtained from Burseraceae species. The scarcity of commercial data and the economic impact of hardened plant exudates obtained from African sources make it difficult to assess the economic contribution they could make to rural households (Lemenih et al., 2003).

\section{Methods}

An outlined chain for the breu production was designed by: i) adapting suggestions on production chains already existing for other forest products; and ii) identifying the actions required to support a dynamic structure, in accordance with the FAO's guidelines. Once the structure for the breu case is visualized and a strategy identified for integration of the various actors, a third step iii) is to foresee the ways through which technological insets can optimize the production chain stages in order to aggregate value. In this context, this study summarizes the keys results reported on the chemical analysis of breu in relation to its commercial and sustainable use. Hence, the exploitation of the Amazonian oleoresins would require the development of three organizational pathways:

\subsection{Outlining the Production Chain}

An initial sketch of a potential production chain for breu is proposed based on existing production chains for other Amazonian NTFPs, in particular certain oilseeds and copaiba oil produced by forest communities (dos Santos \& Guerra, 
2010). Accordingly, three levels were identified to form the chain axis and the conventional flow of activities: extraction (trunk scraping, soil collection), processing, and marketing.

\subsection{Identifying the Issues for Building a Report According to FAO Guidelines}

Considering the chain axis defined by the sequential activities of extraction (primary processing), processing (physical or chemical separation), and commercialization, the main issues to be addressed in order to support these activities are proposed in light of the FAO guidelines for NTFPs. The production and trading of other resins from Burseraceae species, such as Manila elemi, myrrh, olibanum and opoponax (Coppen 1995a, 1995b), were considered as templates. This task highlighted the procedures and techniques related to the collection of the raw material (spontaneous exudates collected directly from the trunks, gathering of pieces of resin detached from the producing trees, or induced tapping); processing the raw material (sub-fragmentation, packaging, transportation); and extraction (separation of the essential oil from the hard resin), packaging, and storing.

\subsection{Seeking Parameters for Breu Standardization}

Data on the physical and chemical composition of breu are reviewed from the scientific literature (Rüdiger et al., 2007; Siani et al., 2012; Rüdiger \& VeigaJúnior, 2013). They are summarized and exemplified by means of data obtained from a commercial sample acquired on the Amazonian market. Data obtained from gas chromatography, infrared and proton magnetic resonance analyses are also provided. Criteria for the standardization of the volatile and nonvolatile breu fractions are summarized. Use of these techniques will contribute toward generating physicochemical certification parameters for the raw material.

\section{Results and Discussion}

\subsection{Outlining the Support of the Production Chain of Breu}

It is well established that non-timber forest products (NTFPs) play an important role in local and national economies in poor and developing countries (Wickens, 1991; Santos et al., 2003). Globally, there have been efforts to valorize non-wood forestry products as a social-economic tool that can positively cause impact the livelihoods of rural people (Barham et al., 1999; Anderson et al., 1999).

Regional and national market studies of NTFPs are available for several Amazonia and Brazilian Savanna products, including andiroba (crabwood oil, Carapa guianensis), murumuru (Astrocaryum murumuru), buriti (miriti), (Palmacea oils, Mauritia flexuosa) (Galdino, 2007), babaçu (Palmaceae, Attalea speciosa), jaborandi (Pilocarpus jaborandi), and other medicinal plants (Afonso \& Ângelo, 2009). These and some other academic studies (Almeida, 2010; Silva, 2014) offer methods that can help establish the production chain of breu and the value chains along the production-trading course. It should also be mentioned 
that NTFPs can be exported by anyone, either a physical or juridical person, as long as they get governmental authorization upon the presentation of the required documentation (Mendonça \& Ferraz, 2006).

Apart from the technical specificities (which, in relation to the volatile fractions, may present commonalities with Manila elemi) (Coppen, 2005a), a productive chain for breu could adopt, as an initial template, that currently in use for copaiba exudate (Copaifera spp.) and several forestry oilseeds, as displayed in Figure 1 (dos Santos \& Guerra, 2010). The few actors involved in this initial scheme reflect the lack of specific knowledge about the potential market for breu, in particular the hard resin. This fact hinders the construction of a fair price chain for breu. However, as has been employed for other raw materials, an initial draft can consider for the following main costs: extraction labor (workers are paid daily); containers for breu storage; freight to transport production to the processing site; and possible taxes (dos Santos \& Guerra, 2010).

At first, more important than establishing or adjusting the price levels and net money aggregation would be certifying the raw material as an NTFP and providing the forest communities access to this certification (Shanley et al., 2005a). Hence, it is first necessary to classify the raw material according criteria that will meet specific market demands. In the case of Manila elemi, the quality of the raw material was designated according to three pricing classes roughly associated

\section{Products to sell out: raw material, essential oil, hard resin, purified material}
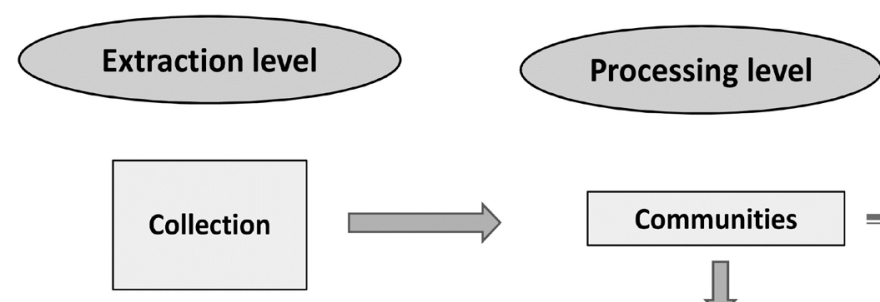

Commercialization level
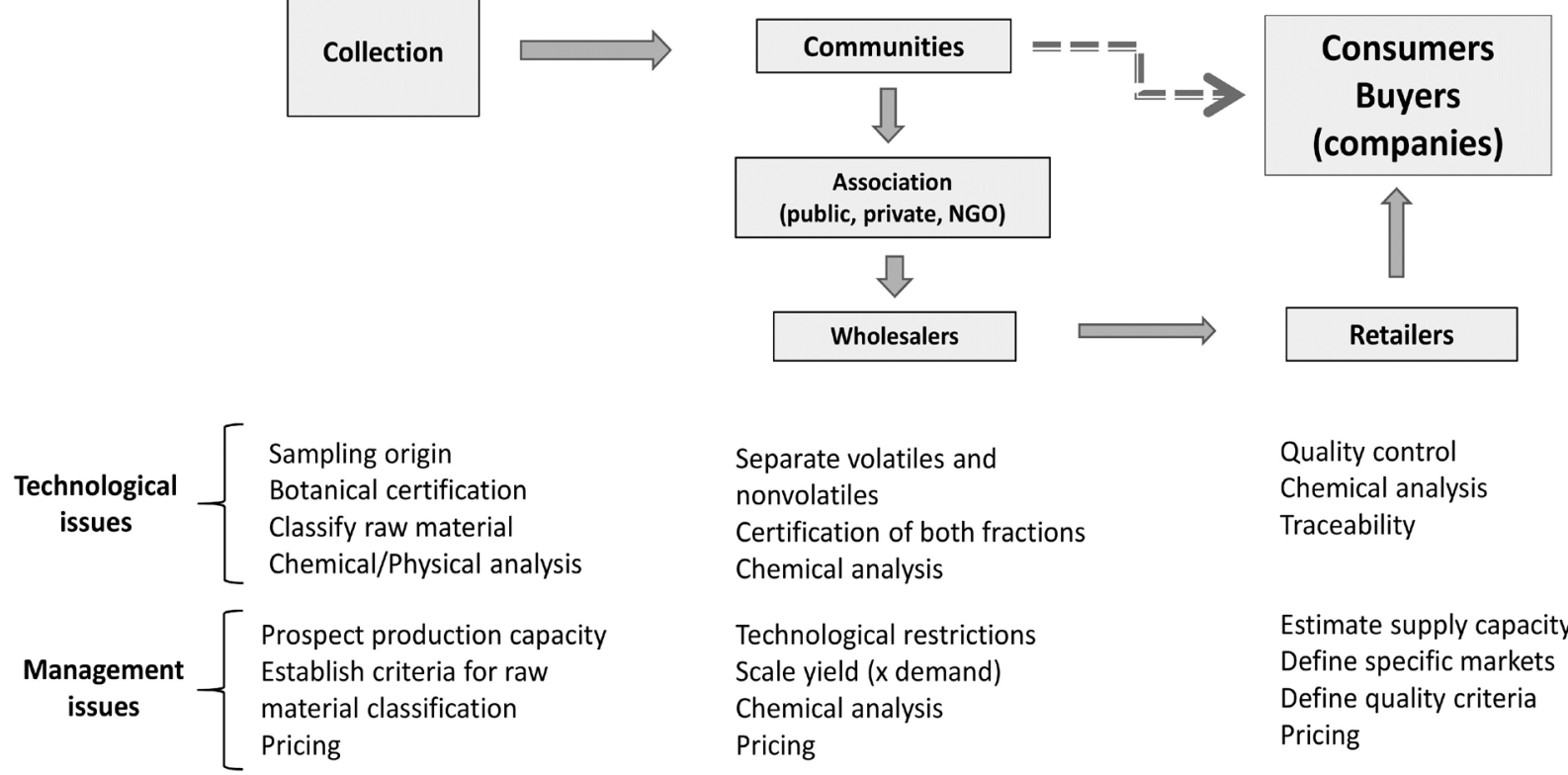

Separate volatiles and nonvolatiles

Certification of both fractions Chemical analysis

Technological restrictions Scale yield ( $x$ demand) Chemical analysis Pricing
Quality control Chemical analysis Traceability

Estimate supply capacity Define specific markets Define quality criteria Pricing

Figure 1. Main agents in the production chain of breu and functional needs (proposition). Elaborated by this article's authors after incorporating concepts suggested in dos Santos \& Guerra (2010) and Silva (2012). 
with degrees of paleness, yellow gradation, and the debris-free condition. Moreover, softer materials are more valuable, reflecting higher contents of essential oil, being the product targeted by the buyers in that case. Thus, comparing breu to this Asiatic oleoresin may bring about more problems than solutions; first, because the fraction of interest does not involve the essential oil; second, it is likely that the above-mentioned pricing criteria for Manila elemi have since been modified (although no updated information is available) (Coppen, 1995a).

Some authors aligned with the concept of Solidary Economy (TFSSE, 2014), have been developing issues of economic and social sustainability for the production of some Amazonian NTFPs, as Brazil nuts and copaiba oil (Silva \& Sampaio, 2012). For Amazonian breu, a similar approach would include identifying or predicting the characteristics of the market structure and the factors that contribute to its optimization; identifying technological restrictions for local production; evaluation of raw material scale-up; and establishing the demand to supply ratio as accurately as possible (Silva, 2012). When building the production chain for breu (indeed, like any other NTFP), effort needs to be directed at resolving the following issues (dos Santos \& Guerra, 2010):

- Lack of product and by-product definitions and descriptions of characteristics.

- Lack of quality control criteria for the raw material (essential to meet highlevel markets).

- Lack of adequate knowledge of the real market for breu and its products.

- Lack of awareness about the valorization of the productive chain downstream. Implementing the appropriate technologies should contribute toward resolving most of these issues by establishing acceptable standards for commercial products. Nevertheless, complementary concerns about general management must be addressed in parallel in order to generate a dynamic production chain; this would entail activities such as:

- Optimization activities (collection, packaging, storing, separation, etc.) to obtain the maximum possible level of good practice.

- Incorporating both broad and specialized sustainability concepts into the production chain activities.

- Setting up collaborations with local academic and technological institutions necessary to perform the required chemical analyses.

- Seeking funds to sustain the multiple activities of the production chain.

- Advocating the political relevance of the breu production chain for forest community economics, since the participation of forest people in production networks has been proven to play an important role in improving their quality of life.

- Development of all concepts from the perspective of international fair trading ethics.

\subsection{Breu Certification and Trading: Main Issues}

Following the FAO guideline, an initial draft on the state-of-the-art of Amazo- 
nian breu production and trade is summarized in the information below. The information is presented according to the standard reporting format. Each section summarizes the data available to date (to the best of our knowledge) and discusses additional details we found pertinent to include.

\subsubsection{Description and Uses}

Crude oleoresin may vary in its physical aspects and properties depending on the relative proportions of monoterpenes and triterpenes. Fresh exudates are liquid that gradually get thick and turn to a soft and malleable solid on exposure to air. Aged exudates (usually found in the highest canopy branches), which have lost their volatile fraction, naturally detach by gravity and fall to the soil beneath the producing tree as hard pieces of whitish solid. This material is basically composed of a mixture of pentacyclic triterpene alcohols and ketones and up to $10 \%$ of tetracyclic elemolic acids, yet it still conserves some residual aroma. In the rain forest, the resin-producing species belonging to the Burseraceae family are especially abundant in Brazil. The crude resin is used as incense, lacquers, and boat caulking material. The volatile extract (essential oil) obtained by distilling the crude resin is used in the flavor and fragrance industries and may be used in the production of perfume, hygiene and disinfecting products. The residue from distillation (as well as the aged hard resin) is utilized in the production of paints, varnishes, and waterproof coating materials. Thus, in order to describe its potential uses, it is first important to clarify the characteristics of the raw material that will then be processed downstream. As a terpenoid resin, the collection yields will vary widely due to the large variability in the mixture of monoand triterpenes in breu constitution (Rüdiger et al., 2009). This means that the demand will directly influence the production chain at its very origin, necessitating a split in the chain gear toward distinct target markets.

The procedures presented here have been currently verified in the municipality of Silves (in the State of Amazonas), where the crude resin is processed to produce essential oil, aromatic sachets, powdered resin repellent candles, and volatile extracts obtained by distillation. These products are sold to medium and small enterprises producing a variety of natural products in Southern Brazil, and to manufacturers of cosmetics and aromatherapy products. Raw resin is eventually sold to manufacturers and individuals to caulk boats.

\subsubsection{World Supply and Demand Trends}

The activities of breu collection and primary processing can be compared, on some level, with those for Manila elemi in the Philippines. Although no recent up-to-date data on such a oleoresin are available, the information contained in the report by the FAO provide a useful example. A physical approach to classifying breu could be considered as used for the Asiatic elemi; however, the industrial separation of volatile from nonvolatile compounds by the buyer would not be foreseen in relation to breu. This process would be expected to the responsibility of the collecting communities and constitutes an important first issue to address in relation to feasible technological improvements. Furthermore, such a 
position would be reinforced by the fact that the collectors should be interested in establishing trade for the hard resin (nonvolatile) prior to selling the essential oil (for which a market already exits). Nevertheless, the production chain for breu could also link up with other production chains already well established by some Amazonian communities, like that for Brazil nuts, copaiba oil, and andiroba oil (Shanley et al., 2005b; Mendonça \& Ferraz, 2006; dos Santos \& Guerra, 2010).

No official data are available relating to the international trade of Amazonian breu. Some initiatives concerned with organizing raw material supply were initiated in some forest communities by a number of industries from the perfumery sector. The companies that foster the breu collecting communities in relation to breu's essential oil have not disclosed details of their adopted practices (that probably include tapping techniques). The hard resin is normally sold in the Amazonian traditional market places. Common sense tells us that different producing trees likely generate different amounts of resin. Ethnobotanical reports have correlated different production yields with breu color and aroma, giving rise to trivial classification scheme: breu branco (white breu), breu preto (black breu) breu vermelho (red breu), breu-manga (mango breu), etc. (Costa, 1975; Corrêa, 1984; Case et al., 2003). The two first (black and white) are the most common and widespread commercial denominations (da Silva et al., 2016).

At present, few communities in the forest region of Silves in the State of Amazonas exploit breu as a means to generating additional income. According to data from the Green Life Association for Amazon (Associação Vida Verde da Amazônia-AVIVE) (UNDP, 2012), approximately 1.5 tons of resin and 15 liters of the distilled essential oil are sold each year. One kilo of crude resin is sold at US\$ 0.7 (Lima et al., 2011). This price attains between US\$ 2.2 and US\$ 3.3 in the largest Amazon cities (dollar prices for 2016), depending on the breu classification. Breu resin can be extracted all year round in the State of Amazonas; Silves being the main municipality dedicated to this activity.

\subsubsection{Plant Sources}

In the rain forest, most of the oleoresin-producing species belong to the genera Protium, Trattinickia, Tetragastris, and Dacryodes (Burseraceae family). The genera Bursera may also be next considered. These trees are commonly known in Brazil as breu-verdadeiro, breu-branco, breu vermelho, breu-manga, gomalimão, jauaricica, almécega, elemi-do-Brasil, incenso-de-Caiena, etc., and in Spanish-speaking Latin American countries as almecega, anine, caraño, animecillo, copal, copalillo, almíscar, galbano, tacahamaca, etc. Usually, these names are associated to the color and the specific aroma of the resin. The trees (e.g. Protium species) grow to between 3 and $40 \mathrm{~m}$ in height (Costa, 1975; Corrêa, 1984; Rizzini \& Mors, 1995). The only sources of oleoresins from these Amazonian Burseraceae species are wild. No cultivation or rational forest management practices have been reported, although some initiatives to cultivate them been tried in Central Amazonia, in Manaus, by INPA (Brazilian Amazonia Research Institute) and EMBRAPA (Brazilian Enterprise on Agropecuary Research). 


\subsubsection{Collection and Primary Processing}

When the raw material is collected with the intent of exploiting its essential oil, the best practices to employ would be determined by quality criteria focused on compositional (and thus aromatic) issues. However, it should also be borne in mind that a low content of volatile oil might account for a higher quality of the harder resin. Thus, a distinct approach to raw material collection is required depending on whether the demand is for volatile or hard breu; this means that the high yield concepts will vary depending on whether the production chain is directed toward the essential oil (flavor and fragrance requirements) or the hard resin (other applications), respectively. Spontaneous soft exudates may be directly collected from the tree trunks, by scratching of the soft material. The use of tapping by incision is sparsely practiced. No systematic data are available on breu productivity, either by specific species or by mixed bulk production. Resin previous cleaning, yields, and factors that would influence the yields need to be better established. Another issue that has yet to be clarified regards biologically-induced resin exudation that occurs when a tree is exposed to attack by certain insects. This phenomenon has been documented in species of Bursera when attacked by chrysomelid beetles (Evans et al., 2000). The insect-induced production of oleoresin in Protium species also has been described by observers and noted in some reports. In a parallel context, the seeds of Protium species are susceptible to infestation by phytophagous braconid wasps (Flores et al., 2005).

In the case of the Silves region, after harvesting the resin, the communities take their resin bags to the administrative headquarters of AVIVE in Saracá Island, where they are electronically weighed and the collection origin is registered by plotting the data on a control sheet. Payment is made directly to the collector (by check), whom must also help check the material for the presence of impurities, such as pieces of wood and other extraneous bodies. It is possible that resin may be rejected if it is deemed not suitable for transformation into a powder. After weighing, checking, and the identification of lots, the selected material is stored in clean fiber bags in a cool dry place. Extraction of the essential oil is carried out by distillation-regarded to be a non-complex technique that can be implemented in the field.

The AVIVE Association, with the support of the European Union, has developed a Manual of Good Forest Management Practices for Non-Loggers (Lima et al., 2011), which provides basic information about the management of various natural products. According to this publication, $3 \mathrm{~kg}$ of crushed breu resin is placed in a $20 \mathrm{~L}$ distiller. For each kilogram of resin, $2 \mathrm{~L}$ of clean water is added into the retort that receives the water vapor produced by a wood-fired boiler during 30 - 60 minutes. The essential oil is separated from the water by placing the still warm mixture into a clean dry plastic container. The pungent essential oil that accumulates at the water surface as a thin film is then separated out and stored in amber glass clean flasks. Essential oils from different collections and distillations make up different lots. On average, $60 \mathrm{~kg}$ of resin will provide 1 liter 
of essential oil, which is priced according to the number of trees managed, time spent in transit to the collection area, the number of people involved, the transport costs to the distillery, and the monitoring activities involved.

\subsubsection{Value-Added Processing}

The proportion of essential oil obtained from crude breu by steam distillation is highly variable. It may range from $2 \%$ to $30 \%$ depending on how aged (hard) or fresh (soft) the resin is (Siani et al., 1999). Fresher resins destined for flavor and fragrance purposes are currently considered more valuable compared with the purposes of hard resin. Thus, one would expect that yield of volatile aromas and malleability, dictated by the essential oil content, would render fresher resins more valuable and deemed to be of a higher quality. However, with the future development of triterpene-based products, a preference for hard, dry, nonvolatile resins may invert this paradigm, with harder raw material eventually becoming superior in value. This discrepancy could be solved by separating breu's volatile and nonvolatile constituents at an early stage in the production chain: soon after collection, whilst it is still held by the collecting communities. A very different situation has evolved in relation to the collection of the terpene-based Manila elemi essential oil (Canarium species) in the Philippines. Importers, in order to justify their wish to distill the oil in their own countries, argued that this product needed to be exported quickly due to the risk that the fresh essential oil may resinify and polymerize (Coppen, 1995a). Nowadays, we can assume that the separation of volatile and nonvolatile fractions is actually feasible in the field through the use of very simple technologies.

\subsubsection{Products Other than Oleoresin}

The aromatic fruits of Protium sp. are considered edible and contain $(>10 \%)$ of essential oil (Siani et al., 2004). The seeds are composed of $25 \%$ of a clear pleasant-tasting fatty oil claimed to be a succedaneum for olive oil (Costa, 1975). The astringent root bark is used in folk therapeutics for renal clearance and its anti-syphilitic properties (Hoene, 1939; Pernet, 1972). The residue left over from the distillation of the essential oil is eventually cheaply sold to either produce incense or be used as a caulking sealant and waterproofing of the wooden hulls of boats. Alternatively, this by-product can be distilled again generating a low quality essential oil. It should be pointed that volatile composition may be altered with the collection time (Albino et al., 2017).

\subsubsection{Development Potential}

The future development of (new) products from hard breu resin is intimately dependent on the execution of research into the general properties of this triterpene-based material. Some analytical tools have already been developed (section 3.3), which may be useful for creating the standards for controlling resin quality (entries i-vii below). This technical approach must be developed aiming the breu quality (entries v-viii below) and, importantly, be supported by economic analysis (entry ix below). The following points constitute the immediate interventions 
necessary to develop future breu markets:

i) Map and compare different Protium species in relation to their productive capacity;

ii) Investigate forest management tools applicable to the Burseraceae species;

iii) Evaluate the adequacy and improve tapping methods;

iv) Introduce, when necessary, improved procedures for: i) primary cleaning of resins gathered from the ground; and ii) the initial packaging of the collected material waiting for proper transportation; both of what are aimed at minimizing loses;

v) Set up studies to: i) provide chemical standards (terpenes); and ii) establish methods and standards for resin at different levels of purification;

vi) Establish standard procedures and protocols for breu quality control;

vii) Establish complementary studies to characterize the physical and chemical characteristics of hard breu as well as its potential to generate varnishes, paints, glues, biofilms, etc.

viii) Research into new uses of the nonvolatile resin;

ix) Proceed with pricing the sub-products of the productive chain in order to incorporate the technology involved;

The requirements listed here correspond to the desires of the extraction communities that collect and process resin in the Central Amazonia. The extractive communities interested in breu collecting (e.g. Silves communities) and commercialization should be increasingly aware of the modern processing technologies associated with the extraction of the essential oil from crude breu. Moreover, the full local production continues to target the domestic market only, since domestic demand remains greater than production. According to players in the industry, there is a need to increase forest inventories for the identification of new areas with breieiros (resin trees) as well as the number of organized extraction communities. Following, there is need to improve facilities for distilling breu in the field; facilitate logistics for the transportation of the materials; improve the products flow; and last but not least, increase the communities' access to financial resources in order to expand production.

\subsubsection{Selected Bibliography}

A bibliography of relevant sources of information has already been compiled and is available in publications focused on Amazonian Burseraceae resins. If need be, the sources could be classified according to key words relating to practical information, such as i) ethnobotany, ii) botanical sources for resin characterization, iii) chemical analysis, and iv) economics. Figure 2 outlines the actions required to support and evolve the development of the breu trade; it starts with actions directed at developing the collection and primary processing activities of Amazonian breu, and ends the activities related to its potential for trading. Accomplishment of these actions should result in the initial valorization of the raw material and reveal the critical points (chain nodes) that need to be improved on, either by increasing the levels of collection and separation good practice or through technological interventions. 


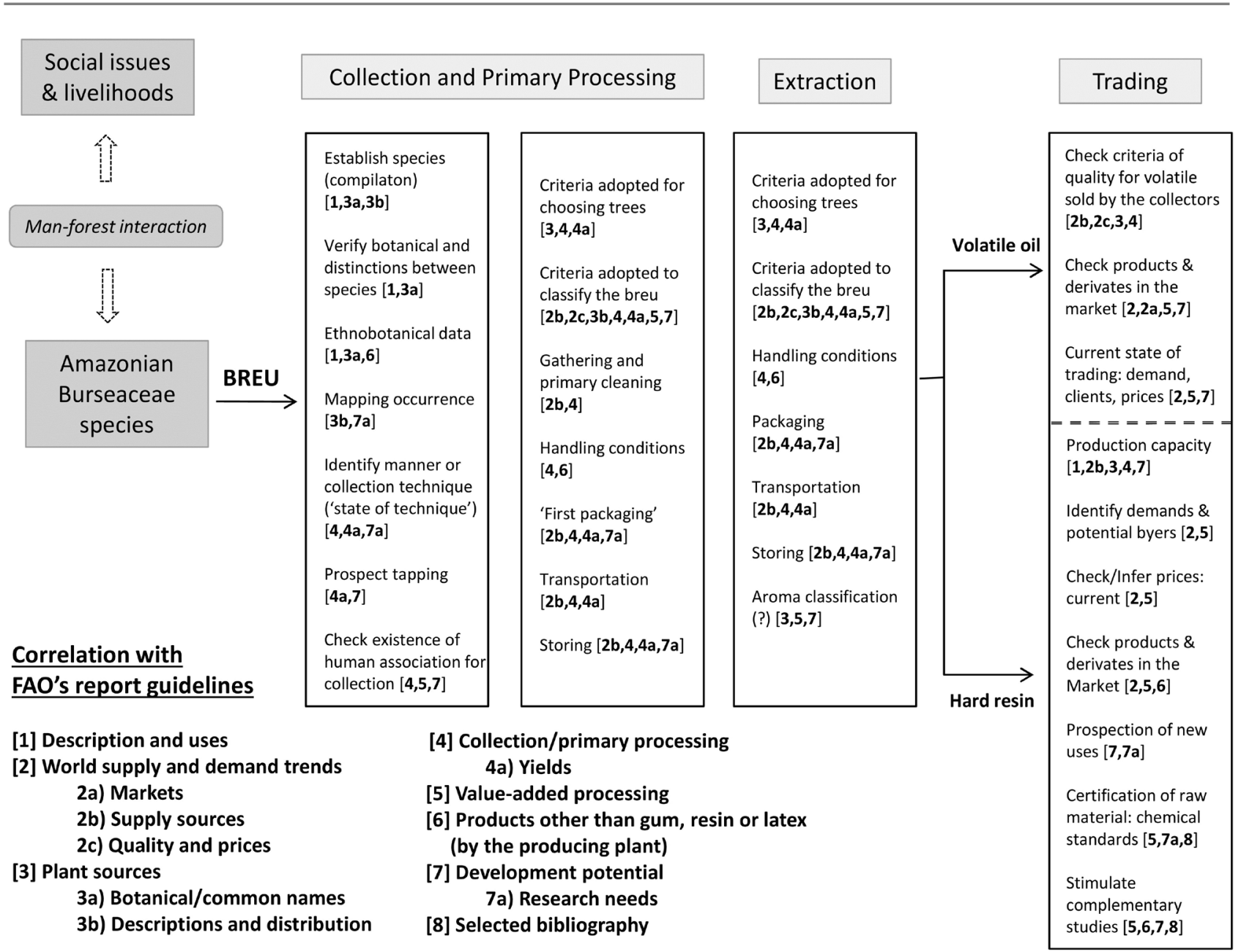

Figure 2. Actions required supporting the development of the breu trade based on the FAO's report guidelines (schemed by this article's authors).

\subsection{Technical Information Related to Breu Quality}

A crucial issue in the task of adding technology to the breu production chain regards raw material certification; this refers to both the original collected material and any downstream sub-product obtained from the separation steps. The parameters for classifying the essential oil are not the focus of this article; instead, what interests us here are the parameters that can reveal the chemical nature of the hard resin. Reports addressing the average chemical composition profiles of hardened breu are already available in the literature (for species from the Protium and other minor genera). Our research groups have developed analytical and statistical tools that can be employed to create these profiles (Rüdiger et al., 2007; Siani et al., 2012; Rüdiger \& Veiga-Júnior, 2013). Depending on the type of harvesting, the hard resin may present around 10\% of debris from inorganic material (sand, mud, etc.), pieces of wood and residual humic acids (when the resin is gathered from the soil). The organic fraction of the resin consists of a mixture of pentacyclic triterpenes, mostly belonging to ursane and oleanane series, along with up to $12 \%$ of tetracyclic elemolic acids (Marques, 2010; Siani et al., 2012) (Figure 3). This fraction is insoluble in water and only partially soluble 


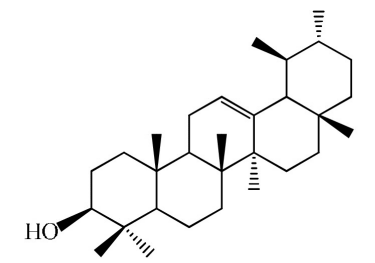

$\alpha$-amyrin $\left(\mathrm{C}_{30} \mathrm{H}_{50} \mathrm{O}, 35-60 \%\right)$

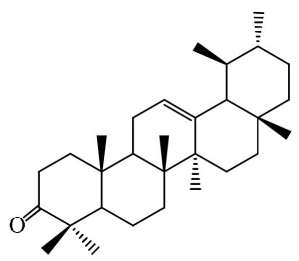

$\alpha$-amyrenone $\left(\mathrm{C}_{30} \mathrm{H}_{48} \mathrm{O} \leq 21 \%\right)$<smiles>CC(C)C1CCC2(C)CCC3C(CCC4C3(C)CCC3C4(C)CC[C@H](C)C3(C)C)C12</smiles>

lupeol $\left(\mathrm{C}_{30} \mathrm{H}_{50} \mathrm{O} \leq 12 \%\right)$

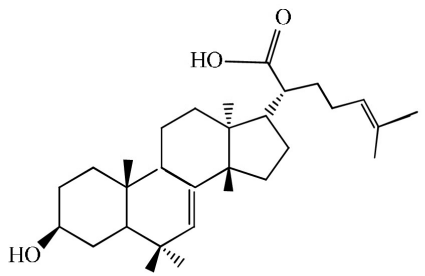

$\alpha$-elemolic acid $\left(\mathrm{C}_{31} \mathrm{H}_{50} \mathrm{O}_{3}<10 \%\right)$

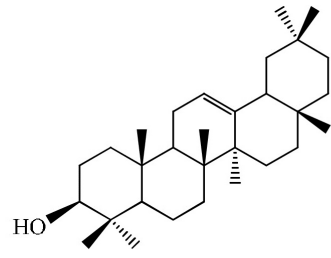

$\beta$-amyrin $\left(\mathrm{C}_{30} \mathrm{H}_{50} \mathrm{O}, 10-30 \%\right)$

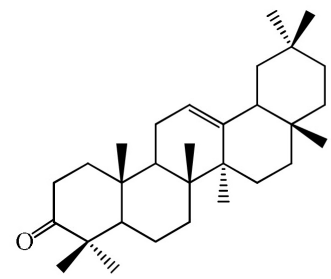

$\beta$-amyrenone $\left(\mathrm{C}_{30} \mathrm{H}_{48} \mathrm{O} \leq 17 \%\right)$

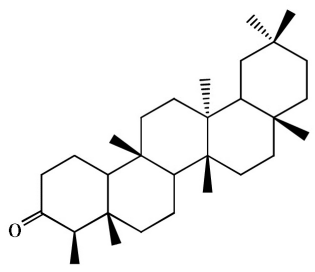

friedelin $\left(\mathrm{C}_{30} \mathrm{H}_{50} \mathrm{O}\right.$ variable $)$

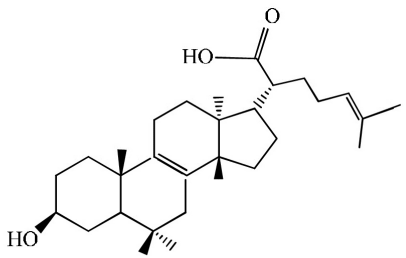

$\beta$-elemolic acid $\left(\mathrm{C}_{31} \mathrm{H}_{50} \mathrm{O}_{3}<13 \%\right)$

Figure 3. Main triterpenes found in the nonvolatile breu fraction (hard resin). Minor compounds include eventual di-hydroxy-triterpenes and other pentacyclic scaffold types. Quantitative variation in the chemical profile occurs according to collection of fresh or aged material (Siani et al., 1999, 2012).

in alcohols, but very soluble in chloroform, ethyl ether, ethyl acetate, and a panel of other lipophilic solvents (Siani et al., 2012).

The isolation of triterpene mixtures from the semi-purified breu mixture is relatively easy to achieve in laboratory by using column chromatography in silica gel; therefore the purification of triterpenes, as a mean to produce standards, is a viable approach and has already been discussed in depth in the literature (Susunaga, 1996; Susunaga et al., 2001; Marques, 2010). In this context, the techniques that resort to the use of chemical standards, such as thin layer chromatography (TLC), gas chromatography (GC), and GC coupled with mass spectrometry (GC-MS) should be used to support the analyses required during the ac- 
tivities of breu collection, separation, and resin commercialization. Figure 4 shows a typical chromatogram as obtained under GC conditions developed by our research group. It was obtained from commercial breu, which constitutes a blend of mixed hard resins without botanical certification and that most probably originated from diverse botanical origins. This approach proved to be suitable, given that there are no significant qualitative differences between hard resins originating from different Protium and Trattinnickia species (Siani et al., 2012).

Proper solvent washing or recrystallization turns the hard resin to a clean white powder that maintains its complex composition. This solid may be analyzed using standard spectrometric techniques, such as TLC, GC, and GC-MS; all of these are suitable techniques for controlling the quality of the raw material. ${ }^{1} \mathrm{H}$ and ${ }^{13} \mathrm{C}$ Nuclear Magnetic Resonance spectroscopy based on the combined of olefinic and carbinol proton absorptions in the spectra (Figure 5) would also be

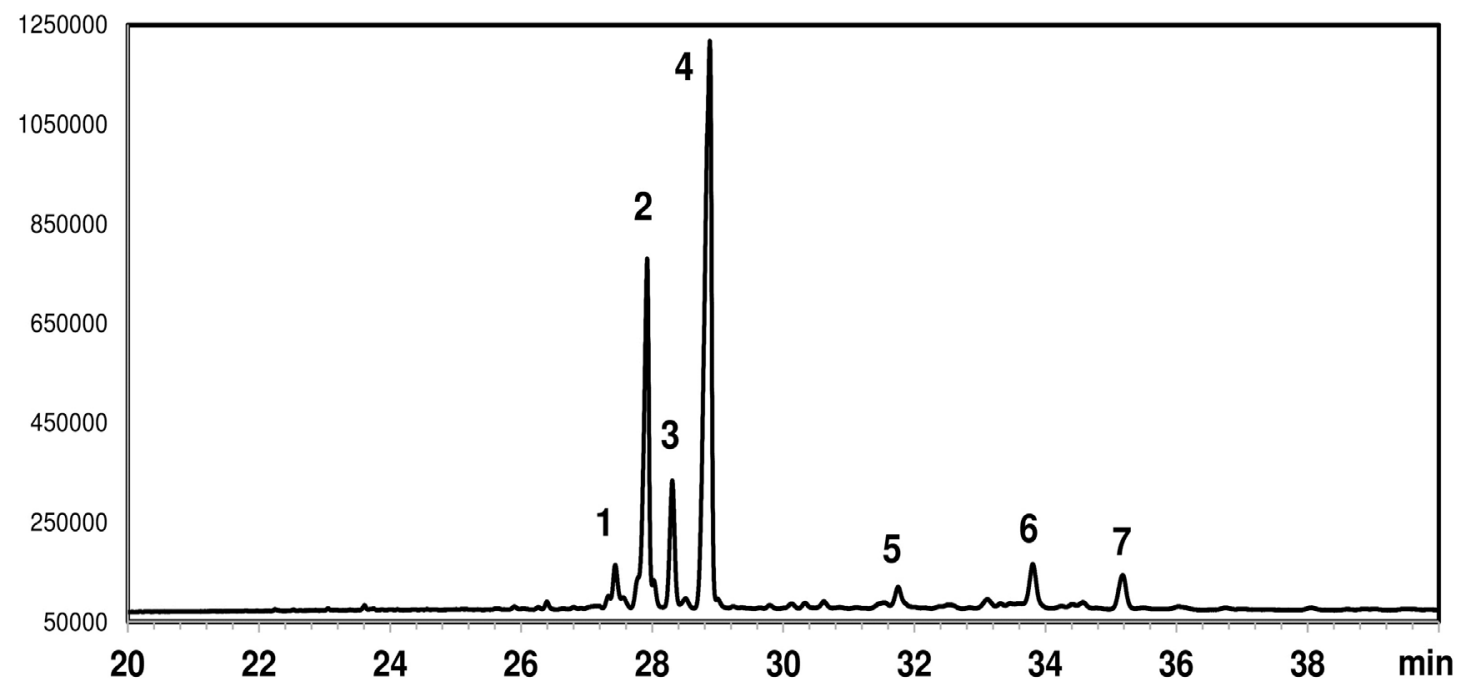

Figure 4. Typical GC chromatogram of commercial breu (hard resin). Obtained in Hewlett-Packard 6890 GC equipment with a HP-5 MS capillary column. Preventive methylation before the injection. Diagnostic signals: 1: $\beta$-amyrenone, 2: $\beta$-amyrin, 3: $\alpha$-amyrenone, 4: $\alpha$-amyrin + lupeol, 5: friedelin, 6 and 7: dihydroxytriterpenes. For identification of minor signals, see Siani et al. (2012) (elaborated by the authors, from laboratory results).

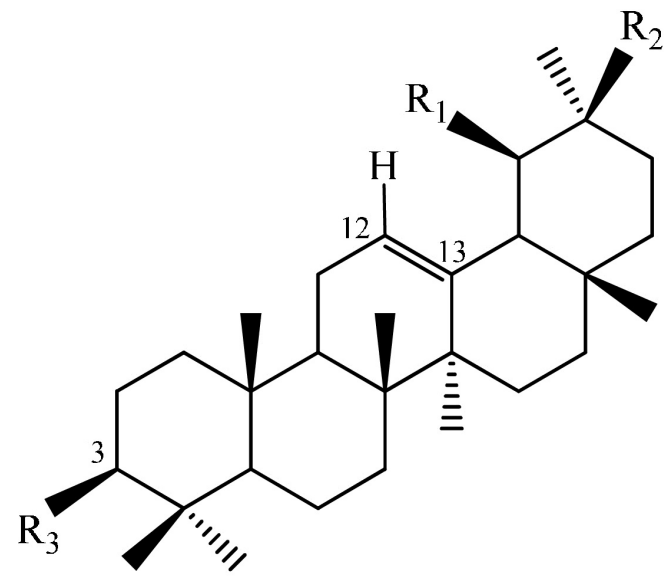

Diagnostic peaks in oleanane/ursane series

\begin{tabular}{lcr} 
& \multicolumn{1}{c}{${ }^{1} \mathbf{H}$} & \multicolumn{1}{c}{${ }^{13} \mathbf{C}$} \\
\cline { 2 - 3 } position 3 $(\mathrm{OH})$ & $3.0-3.2(\mathrm{dd})$ & $78-80 \mathrm{ppm}$ \\
position 3 $(=\mathrm{O})$ & - & $217-219 \mathrm{ppm}$ \\
position 12 & $3.0-3.2(\mathrm{dd})$ & $121-125 \mathrm{ppm}$ \\
position 13 & - & $139-146 \mathrm{ppm}$
\end{tabular}

\begin{tabular}{lccl}
$\mathbf{R} 1$ & $\mathbf{R} 2$ & $\mathbf{R 3}$ & \\
\cline { 1 - 2 } & $\mathrm{CH}_{3}$ & $\mathrm{O}$ & $-\beta$-amyrenone \\
$\mathrm{H}$ & $\mathrm{CH}_{3}$ & $\mathrm{OH}$ & $-\beta$-amyrin \\
$\mathrm{CH}_{3}$ & $\mathrm{H}$ & $\mathrm{O}$ & $-\alpha$-amyrenone \\
$\mathrm{CH}_{3}$ & $\mathrm{H}$ & $\mathrm{OH}-\alpha$-amyrin
\end{tabular}

Figure 5. NMR diagnostic signals for triterpene constituents of commercial breu (hard resin). Based in the characteristic predominance of amyrins. 


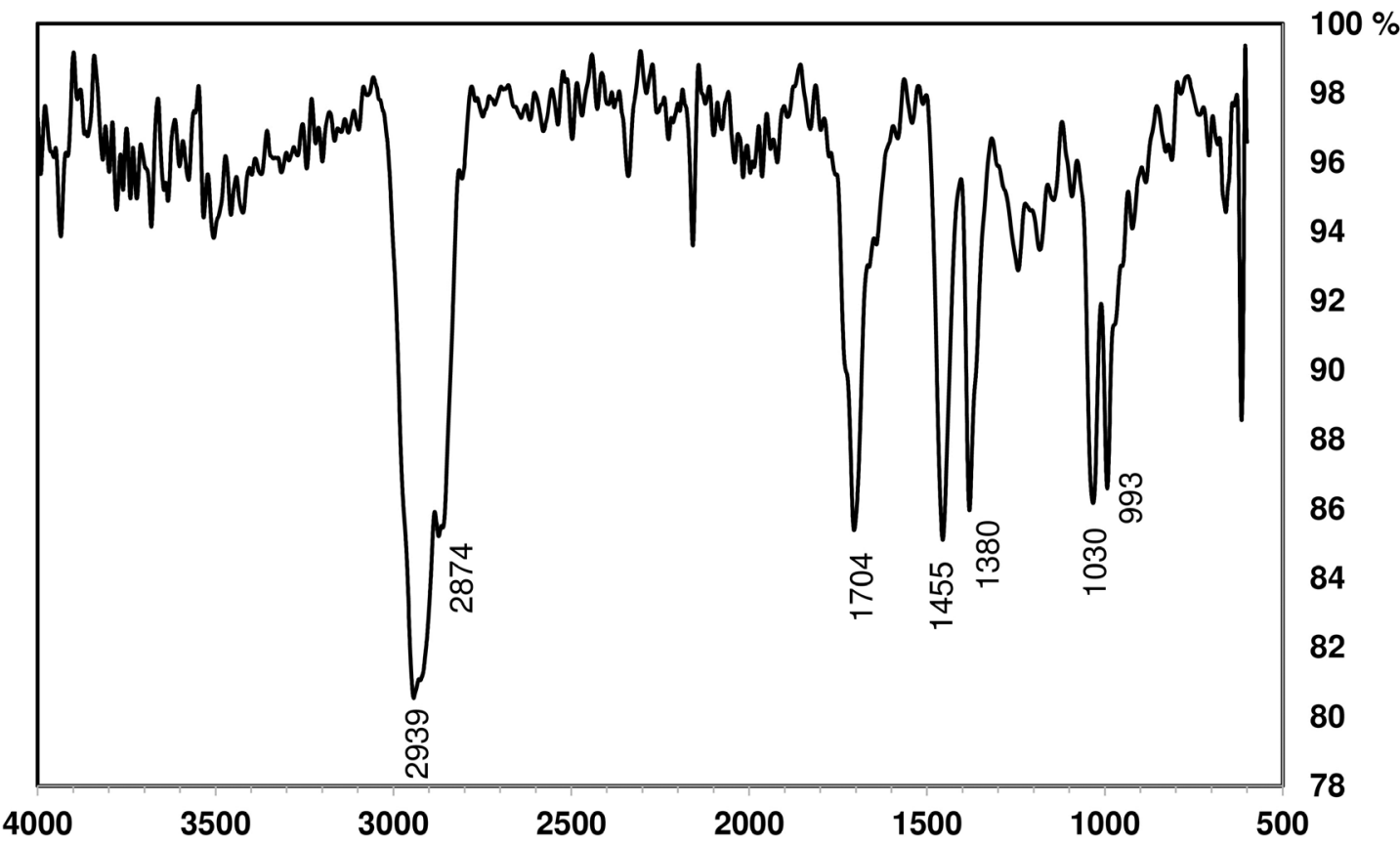

Figure 6. Typical infrared spectrum of commercial breu (hard resin). Spectrum obtained in a Nicolet FT-IR 670 spectrometer. Main bands (KBr pellet, $\mathrm{cm}^{-1}$ ) at 2939 (b,s), 28743 (b,s), 1704 - 1650 (split, m), 1455 (m), 1380 $(\mathrm{m}), 1030(\mathrm{~m}), 933(\mathrm{~m}) \mathrm{cm}^{-1}$. Depending on the sample's purity degree, some close bands could be less distinctly split or vary the intensity (elaborated by the authors, from laboratory results).

useful for qualitative analysis of the mixture, but no quantitative tool based on these techniques has been developed to date. Infrared spectroscopy (FT-IR) (Figure 6) applied to triterpene mixtures has yet to be explored in depth; only Langelheim (2003) has mentioned its application in relation to other resins.

The techniques presented herein were suitable for analyzing a mixture of triterpenes and will be able to establish the necessary parameters for the standardization of hard resin. Hence, they could afford feasible support to establish criteria for marketing the non-volatile material at higher quality level. These analyses have not yet been applied in breu production chains anywhere, and suitable formats for the certification of the raw material, its products and sub-products must still be identified. Few useful manuals concerning the production of essential oil from breu have been sponsored by Associations' initiatives and governmental support (Schmal et al., 2006; Lima et al., 2011). Furthermore, academic studies on the essential oil or other general resin aspects have been addressed in elsewhere reports (Siani et al., 1999; Ramos et al., 2000; Case et al., 2003). Nevertheless, to date, no protocol seems to have been followed as a practical approach to hard resin assessment, other than ethnobotanical assumptions and unofficial communications.

\section{Conclusion}

The present study addresses Amazonian oleoresins produced by species of Burseraceae. Unlike the well-established production systems for various Asiatic and African resins, to the best of our knowledge, no initiatives exist aimed at creating 
similar contexts for rainforest breu. Once breu quality assessments incorporate sustainability as a fundamental criterion, especially in the production process, the higher its potential will be to generate products for the market.

Two central points are equally important in such a scenario. The first regards the technical aspects of the product to be sold. In the context, relevant scientific information already exists that can be applied either to the raw collected breu or to semi-purified intermediates, aimed at its early valorization. Comparison with chemically similar materials already being traded internationally could be helpful (e.g. Asian or African oleoresins), despite the fact that the majority of information available are focused on breu's volatile fraction. The studies developed by our research groups will help advance these aspects. Secondly, these accomplishments are inherently connected to good performance in the activities of raw material collection, handling, packing, transportation, and storage. That means that the process, as a whole, must be certified and achieve certain standards.

Due to its relevance, the breu production chain should be included in general and trans-sector NTFP policies involving governmental organisms from the Departments for Agriculture, Environment, Commerce \& Industry, Social Development, etc. in order to integrate action at the federal, state, and municipal levels (Souza, 2012). The exploitation of the NTPFPs is a compelling vocation of the forest peoples (Fiedler et al., 2010). It is sufficient one to note how historically this activity has determined the economic cycles up to the present day, of which the more remarkable paradigm was the Amazon Rubber Boom (Pinto et al., 2012). In the forests, sustainability should be inherent to a well-fared society; this achievement arising more ready and steady in the forest communities where local cooperation prevails, by integrating concepts of production forest (multiple use), protection forest (management regimes) and conservation area (biodiversity, soil and water conservation) (Adusei \& Dunyah, 2016). In this sense, establishing the commercial chains of forest products (from harvesting site up to final consumers) make up one of the paradigms over which a strong support to forest certification programs is built (Watts et al., 2012).

\section{References}

Adusei, C., \& Dunyah, J. Y. (2016). Forest Fringe Communities Participation in Forest Reserve Sustainability in Ghana. Open Journal of Forestry, 6, 94. https://doi.org/10.4236/ojf.2016.62009

Afonso, S. R., \& Ângelo, H. (2009). Market of Non-Wood Forest Products from the Brazilian Savanna. Ciência Florestal (Santa Maria), 19, 315-326.

Albino, R. C., Oliveira, P. C., Prosdocimi, F., da Silva, O. F., Bizzo, H. R., Gama, P. E., Sakuragui, C. M., Furtado, C., \& de Oliveira, D. R. (2017). Oxidation of Monoterpenes in Protium heptaphyllum Oleoresins. Phytochemistry, 136, 141-146.

Almeida, L. S. (2010). Non-Timber Forest Products in Managed Area: Analysis of a Community in the Region of Influence of BR 163 Road, Santarém, State of Pará. M.Sc. Thesis, Belém: Universidade Federal Rural da Amazônia.

Anderson, J., Warner, K., Russo, L., \& Qwist-Hoffmann, H. (1999). The Challenges of Extension for Non-Wood Forest Products (pp. 54-57). Rome: UNASYLVA-FAO. 
Barham, B. L., Coomes, O. T., \& Takasaki, K. (1999). Rain Forest Livelihoods: Income Generation, Household Wealth and Forest Use (pp. 34-42). Rome: UNASYLVA-FAO.

Carranza, J. A. Q., \& Alejandro, M. A. M. (2015). Natural Resins of Mexican Plant Species: Current and Potential End-Uses. Madera y Bosques, 21, 171-183.

Case, R. J., Tucker, A. O., Maciarello, M. J., \& Wheeler, K. A. (2003). Chemistry and Ethnobotany of Commercial Incense Copals, Copal Blanco, Copal Oro, and Copal Negro, of North America. Economic Botany, 57, 189-202. https://doi.org/10.1663/0013-0001(2003)057[0189:CAEOCI]2.0.CO;2

Coppen, J. J. (1995a). Gums, Resins and Latexes of Plant Origin. Non-Wood Forest Products 6. Rome: FAO.

Coppen, J. J. W. (1995b). Non-Wood Forest Products 1: Flavours and Fragrances of Plant Origin. Rome: FAO.

Coppen, J. J. W., \& Hone, G. A. (1995). Non-Wood Forest Products 2. Gum Naval Stores: Turpentine and Rosinfrom Pine Resin. Rome: FAO.

Corrêa, P. (1984). Dictionary of Useful Native Plants and Cultivated Exotic Plants in Brazil (Vol. 1). Rio de Janeiro: Imprensa Nacional, Ministério da Agricultura.

Costa, A. F.(1975). Farmacognosia (Vol. 1). Lisboa: Fundação CalousteGulbenkian.

Da Silva, E. R., de Oliveira, D. R., Melo, M. D. F. F., Bizzo, H. R., \& Leitão, S. G. (2016). Report on the Malungo Expedition to the Erepecuru River, Oriximiná, Brazil. Part I: Is There a Difference between Black and White Breu? Brazilian Journal of Pharmacognosy, 26, 647-656. https://doi.org/10.1016/j.bjp.2016.05.003

Daly, D. C. (2007). A New Section of Protium from the Neotropics. Studies in Neotropical Burseraceae XIII. Brittonia, 59, 1-24. https://doi.org/10.1663/0007-196X(2007)59[1:ANSOPF]2.0.CO;2

Dos Santos, A. J., \& de Queiroz Guerra, F. G. P. (2010). Economical Aspects of the Productive Chain of Oils of Andiroba and Copaiba in the National Forest of the Tapajos-Para. Floresta, 40, 23-28.

Evans, P. H., Becerra, J. X., Venable, D. L., \& Bowers, W. S. (2000). Chemical Analysis of Squirt-Gun Defense in Bursera and Counter Defense by Chrysomelid Beetles. Journal of Chemical Ecology, 26, 745-754. https://doi.org/10.1023/A:1005436523770

Fiedler, N. C., Soares, T. S., \& da Silva, G. F. (2010). Non-Timber Forest Products: Significance and Sustainable Management of Forest. RECEN-Revista Ciências Exatas e Naturais, 10, 263-278.

Flores, S., Nassar, J. M., \& Quicke, D. L. (2005). Reproductive Phenology and Pre-Dispersal Seed-Feeding in Protium tovarense (Burseraceae), with a Description of the First Known Phytophagous "Bracon" Species (Hymenoptera: Braconidae: Braconinae). Journal of Natural History, 39, 3663-3685. https://doi.org/10.1080/00222930500392659

Frisk, T. (1995). Consultation of Experts on Non-Wood Forest Products for Latin America and the Caribbean. Santiago: Serie Forestal no 1. Oficina de la FAO para America Latina y Caribe. http://www.fao.org/docrep/t2354s/t2354s00.htm

Galdino, A. P. P. (2007). Market Study: Andiroba, Buriti/Miriti, Murumuru. https://projects.ncsu.edu/project/amazonia/brazil_proj/Result/Estudo_de_Mercado_A PGaldino.pdf

Hernández-Vázquez, L., Mangas, S., Palazón, J., \& Navarro-Ocaña, A. (2010). Valuable Medicinal Plants and Resins: Commercial Phytochemicals with Bioactive Properties. Industrial Crops and Products, 31, 476-480.

https://doi.org/10.1016/j.indcrop.2010.01.009

Hoene, F. C. (1939). Toxic and Medicinal Plants and Plant Substances. São Paulo: Gra- 
phicars.

Khalid, S. A. (1983). Chemistry of the Burseraceae. In P. G. Waterman, \& M. F. Grundon (Eds.), Chemistry and Chemical Taxonomy of the Rutales (pp. 281-299). London: Academic Press.

Lago, J. H. G., Tezoto, J., Yazbek, P. B., Cassas, F., Santos, J. D. F., \& Rodrigues, E. (2016). Exudates Used as Medicine by the "Caboclos River-Dwellers" of the Unini River, AM, Brazil-Classification Based in Their Chemical Composition. Brazilian Journal of Pharmacognosy, 26, 379-384.

Langenheim, J. H. (2003). Plant Resins: Chemistry, Evolution and Ethobotany. Portland, OR: Timber Press, Inc.

Le Cointe, P. (1947). Trees and Useful Plants: Indigenous and Acclimated. Belém: Livraria Clássica.

Lemenih, M., Abebe, T., \& Olsson, M. (2003). Gum and Resin Resources from Some Acacia, Boswellia and Commiphora Species and Their Economic Contributions in Liban, Southeast Ethiopia. Journal of Arid Environments, 55, 465-482. https://doi.org/10.1016/S0140-1963(03)00053-3

Lewis, W. H., \& Elvin-Lewis, M. P. (1977). Medical Botany: Plants Affecting Man’s Health. New York, NY: John Wiley \& Sons.

Lima, K. F., Batista, M. J. N., Schmal, B., \& Schmal, P. (2011). Manual of Good Practices in Non-Lumber Forest Management (56 p.). Silves, AM: Associação Vida Verde da Amazônia AVIVE.

Marques, D. D. (2010). Contribution to the Chemical Knowledge of the Acre Flora: Protium hebetatum Daly, Protium heptaphyllum (Aublet) Marchand subsp. ulei (Swat) and Daly Protium heptaphyllum (Aublet) Marchand subsp. heptaphyllum. Doctorate Thesis, Fortaleza: Universidade Federal do Ceará.

Marques, D. D., Graebner, I. B., de Lemos, T. L., Machado, L. L., Assuncao, J. C., \& Monte, F. J. (2010). Triterpenes from Protium hebetatum Resin. Natural Product Communications, 5, 1181-1182.

Mendonça, A. P., \& Ferraz, I. D. K. (2006). Crabwood Oil Export Procedure in Amazonas State. Revista Fitos, 2, 42-45.

Murthy, K. S. R., Reddy, M. C., Rani, S. S., \& Pullaiah, T. (2016). Bioactive Principles and Biological Properties of Essential Oils of Burseraceae: A Review. Journal of Pharmacognosy and Phytochemistry, 5, 247.

Pernet, R. (1972). Phytochimiedes Burseracees. Lloydia, 35, 280-287.

Pinto, A., Amaral, P., Gaia, C., \& Oliveira, W. D. (2012). Good Practices for Forest and Agroindustrial Management of Non-Timber Forest Products: Açaí, Andiroba, Babaçu, Brazil Nuts, Copaiba and Cat's Claw. Belém, PA: Imazon/Sebrae.

Ramos, M. F. S., Siani, A. C., Tappin, M. R. R., Guimarães, A. C., \& Ribeiro, J. E L. S. (2000). Essential Oils from Oleoresins of Protium spp. of the Amazon Region. Flavour and Fragrance Journal, 15, 383-387. https://doi.org/10.1002/1099-1026(200011/12)15:6<383::AID-FFJ927>3.0.CO;2-X

Rhind, J. P. (2013). Fragrance and Wellbeing: Plant Aromatics and Their Influence on the Psyche. London: Singing Dragon.

Rizzini, C. T., \& Mors, W. B. (1995). Botânica Econômica Brasileira (pp. 112-113). Rio de Janeiro: Âmbito Cultural.

Rüdiger, A. L., \& Veiga-Junior, V. F. (2013). Chemodiversity of Ursane- and OleananeType Triterpenes in Amazonian Burseraceae Oleoresins. Chemistry \& Biodiversity, 10, 1142-1153. https://doi.org/10.1002/cbdv.201200315

Rüdiger, A., \& Veiga-Junior, V. F. (2009). Chemical Constituents and Pharmacology of 
the Neotropical Burseraceae. Compendium of Bioactive Natural Products: Extraction, Isolation \& Characterization, 6, 1-23.

Rüdiger, A.L., Siani, A. C., \& Veiga-Junior, V. F. (2007).The Chemistry and Pharmacology of the South America Genus Protium Burm. F. (Burseraceae). Pharmacognosy Reviews, 1, 93-104.

Santos, A. J., Hildebrand, E., Pacheco, C. H. P., Pires, P. T. L., \& Rochadelli, R. (2003). Non-Wood Products: Concepts, Classification, Economic Valuation and Markets. Revista Floresta, 33, 215-224.

Schmal, B., Campos, E. A., Batista, M. J. N., \& Silva, V. R. (2006). Community Management of Non-Timber Forest Products and Local Strengthening in the Municipality of Silves-AM. Project: Amazonian Oils and Smells of the Forest in Small Flasks.

http://docplayer.com.br/12405091-Oleos-da-amazonia-os-cheiros-da-floresta-em-vidri nhos.html

Shanley, P., Cymerys, M., Serra, M., \& Medin, G. (2005b). Fruit Trees and Useful Plants in Amazonian Life. Non-Wood Forest Products 20. Rome: FAO.

Shanley, P., Pierce, A., \& Laird, S. (2005a). Beyond Wood: Certification of Non-Timber Forest Products. Bogor: Center for International Forestry Research (CIFOR).

Siani, A. C., Garrido, I. S., Monteiro, S. S., Carvalho, E. S., \& Ramos, M. F. (2004). Protium icicariba as a Source of Volatile Essences. Biochemical Systematics and Ecology, 32, 477-489. https://doi.org/10.1016/j.bse.2003.11.003

Siani, A. C., Nakamura, M. J., Tappin, M. R. R., Monteiro, S. S., Guimarães, A. C., \& Ramos, M. F. S. (2012). Chemical Composition of South American Burseraceae NonVolatile Oleoresins and Preliminary Solubility Assessment of Their Commercial Blend. Phytochemical Analysis, 23, 529-539. https://doi.org/10.1002/pca.2351

Siani, A. C., Ramos, M. F., Guimarães, A. C., Susunaga, G. S., \& Zoghbi, M. D. G. (1999). Volatile Constituents from Oleoresin of Protium heptaphyllum (Aubl.) March. Journal of Essential Oil Research, 11, 72-74. https://doi.org/10.1080/10412905.1999.9701075

Silva, C. K. (2014). Production and Management of Two Potential Non-Timber Forest Products in the Amazon Contexto-the Cipó-Titica (Heteropsis spp.) and copaiba (Copaifera spp.). Doctoral Thesis, Piracicaba: Universidade de São Paulo-ESALQ.

Silva, L. M. (2012). Sustainability in the Brazilian Amazon. Santander Práticas de Educação para Sustentabilidade, Caso Prático, Universidade Estadual do Amazonas. http://praticasdeeducacao.universia.com.br/projetos/detalhe/68/A-SUSTENTABILIDA DE-NA-AMAZONIA-BRASILEIRA

Silva, L. M., \& Sampaio, P. T. B. (2012). Solidarity Economy, Extractivism and Development in the Southern Brazilian Amazon. In II Encontro Nacional de Pesquisa sobre Economia Solidária. https://abpes.files.wordpress.com/2013/12/33.pdf

Souza, F. M. (2012). Socioeconomic Characteristics and Environmental Non Timber Forest Products Agroextractive of Families in Four Cities of Goiás. M.Sc. Thesis, Brasília: Universidade de Brasília.

Susunaga, G. S. (1996). Chemical and Biological Study of the Resin Produced by the Species Protium heptaphyllum March. (Burseraceae). M.Sc. Thesis, Manaus: Universidade Federal do Amazonas.

Susunaga, G. S., Siani, A. C., Pizzolatti, M. G., Yunes, R. A., \& Delle Monache, F. (2001). Triterpenes from the Resin of Protium heptaphyllum. Fitoterapia, 72, 709-711. https://doi.org/10.1016/S0367-326X(01)00289-1

TFSSE (2014). Social and Solidarity Economy and the Challenge of Sustainable Development. A Position Paper by the United Nations Inter-Agency Task Force on Social and 
Solidarity Economy (TFSSE).

http://unsse.org/wp-content/uploads/2014/08/Position-Paper_TFSSE_Eng1.pdf

UNDP (2012). Equator Initiative Case Studies: Green Life Association of Amazonia (AVIVE), Brazil.

https://pt.scribd.com/document/180224601/Case-Studies-UNDP-GREEN-LIFE-ASSO CIATION-OF-AMAZONIA-AVIVE-Brazil

Watts, C. M., Pile, L. S., \& Straka, T. J. (2012). Sustainability and Forest Certification as a Framework for a Capstone Forest Resource Management Plans Course. Open Journal of Forestry, 2, 159. https://doi.org/10.4236/ojf.2012.23019

Submit or recommend next manuscript to SCIRP and we will provide best service for you:

Accepting pre-submission inquiries through Email, Facebook, LinkedIn, Twitter, etc. A wide selection of journals (inclusive of 9 subjects, more than 200 journals)

Providing 24-hour high-quality service

User-friendly online submission system

Fair and swift peer-review system

Efficient typesetting and proofreading procedure

Display of the result of downloads and visits, as well as the number of cited articles Maximum dissemination of your research work

Submit your manuscript at: http://papersubmission.scirp.org/

Or contact ojf@scirp.org 